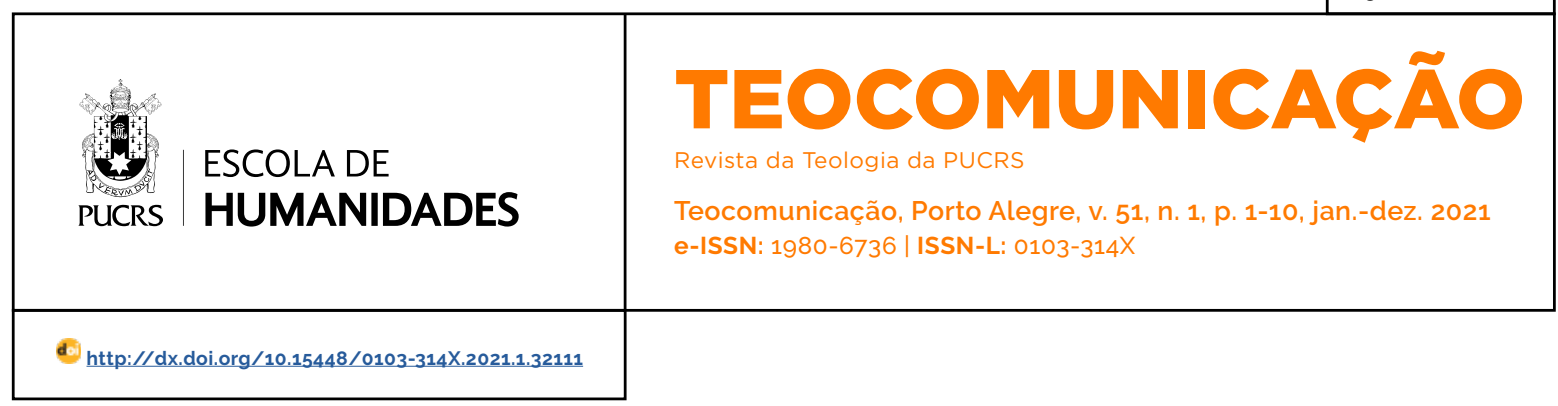

SEÇÃO: TEMÁTICA LIVRE

\title{
O anúncio como uma dimensão da pastoral escolar
}

The announcement as a dimension of school pastoral

\author{
El anuncio como dimensión de la pastoral escolar
}

\section{Sérgio Rogério Azevedo Junqueira ${ }^{1}$}

orcid.org/0000-0003-2168-1186

srjunq@gmail.com

\section{Terezinha Sueli de \\ Jesus Rocha ${ }^{1}$}

orcid.org/0000-0001-7986-7210

terezinhasuelirocha@yahoo. com.br

Recebido em: 01/10/2018.

Aprovado em: 17/11/2020.

Publicado em: 27/09/2021.

\section{(c) (i)}

Artigo está licenciado sob forma de uma licença Creative Commons Atribuição 4.0 Internacional.
Resumo: Este artigo decorre do programa História e Concepções da Educação Religiosa, conduzido pelo Grupo de Pesquisa em Educação e Religião. A pesquisa desenvolvida e aqui apresentada teve como referência uma abordagem qualitativa e se utilizou do método bibliográfico e documental de identificação de informações objetivando reconhecer a importância do anúncio na dinâmica educacional da escola católica. Neste aspecto evidenciamos a característica do anúncio com o olhar de Jesus Cristo que não faz distinção, pois todos somos irmãos em Cristo, portanto olhando, amando e agindo como Jesus o anúncio alcançará seu objetivo. A alegria do Evangelho contém sempre a dinâmica do êxodo e do dom, de sair de si mesmo, de caminhar e de semear sempre de novo, semear sempre mais além. Dentro do movimento de sair de si estabelecem-se conexões com a cultura da humanidade e nela se inserem atitudes dialógicas, pois o anúncio carrega em si a capacidade de interagir com a sociedade acolhendo a diversidade cultural e assumindo a mediação da caminhada rumo à edificação do Reino de Deus. O anúncio do Evangelho exige o encarnar-se na cultura própria de cada espaço onde se quer evangelizar e um espaço especialmente preparado para o anúncio acontecer é a Escola Católica, pois reúne condições especiais por contar com um público em busca do conhecimento como forma de viver as verdades da ciência e da fé.

Palavras-chave: Educação confessional. Pastoral escolar. Anúncio.

Abstract: This article stems from the program "History and Conceptions of Religious Education", conducted by the Education and Religion Research Group (IPFER). The research developed and presented here had as a reference a qualitative approach and the bibliographical and documentary method of information identification was used to recognize the importance of the advertisement in the educational dynamics of the Catholic School. In this aspect we show the characteristic of the announcement with the look of Jesus Christ that makes no distinction, for we are all brothers in Christ, therefore looking, loving and acting like Jesus, the announcement will reach its goal. "The joy of the Gospel always contains the dynamics of the exodus and of the gift, of going out of oneself, of walking and of sowing ever again, of sowing ever further" (EG 21). Within the movement of leaving oneself they establish themselves connections with the culture of mankind and in it are inserted dialogical attitudes, for the advertisement carries within itself the ability to interact with society by welcoming cultural diversity and assuming the mediation of the journey towards the edification of the Kingdom of God. The proclamation of the Gospel requires embodying itself in the culture proper to each space where one wants to evangelize and a space specially prepared for the announcement to take place is the Catholic School, since it meets special conditions by having an audience in search of knowledge as a way of living the truths of science and faith.

Keywords: Confessional education. Pastoral school. Advertisement.

Resumen: Este artículo es parte del programa Historia y Concepciones de la Educación Religiosa, realizado por el Grupo de Investigación en Educación y Religión. La investigación desarrollada y presentada aqui se basó en un enfoque cualitativo y utilizó el método bibliográfico y documental de identificación de 
información con el fin de reconocer la importancia de la publicidad en la dinámica educativa de la Escuela Católica. En este aspecto, destacamos la caracteristica del anuncio con la mirada de Jesucristo que no hace distinciones, pues todos somos hermanos en Cristo, por tanto, mirando, amando y actuando como Jesús, el anuncio alcanzará su objetivo. La alegría del Evangelio contiene siempre la dinámica del éxodo y el don, de salir de uno mismo, de caminar y siempre sembrar de nuevo, siempre de sembrar más allá. Dentro do movimento de sair de si estabelecem-se conexões com a cultura da humanidade e nela se inserem atitudes dialógicas, pois o anúncio carrega em si a capacidade de interagir com a sociedade acolhendo a diversidade cultural e assumindo a mediação da caminhada rumo à edificação do Reino de Dios. El anuncio del Evangelio requiere encarnarse en la cultura de cada espacio donde se quiere evangelizar y un espacio especialmente preparado para que suceda el anuncio es la Escuela Católica, ya que tiene unas condiciones especiales para tener un público en busca del conocimiento como vía de viviendo las verdades de la ciencia y la fe.

Palabras clave: Educación confesional. Pastoral escolar. Anuncio.

\section{Introdução}

Os pesquisadores do Instituto de Pesquisa e Formação Educação e Religião, IPFER desde 1996 realizam estudos e pesquisas para estabelecer a origem e desenvolvimento da Pastoral Escolar, no contexto histórico das escolas confessionais católicas brasileiras, assim como desenvolver a estrutura e fundamentos pedagógicos, teológicos e de articulação no cotidiano escolar, atualmente, o processo visa definir questões metodológicas. Para explicitar esta proposta o IPFER publicou alguns textos para dialogar sobre as dimensões que explicitam a Pastoral Escolar, porém com o avanço do projeto verificou-se a importância de melhor definir cada uma dessas dimensões no contexto da compreensão de confessionalidade nas instituições de educação básica com a especificidade da educação confessional, espaço em que está inserida a Pastoral.

Compreendendo que no Brasil, a educação escolar confessional é garantida pelo Art. 213 da Constituição Federativa do Brasil de 19881 e pela Lei de Diretrizes e Bases da Educação Nacional, na qual o artigo $20^{\circ}$ assegura o direito às instituições de ensino privado a exercerem atividades de cunho religioso e confessional. A instituição escolar confessional pressupõe um credo e uma religião, pois adota uma confissão explicita no desempenho de suas atividades que assume na perspectiva da espiritualidade. Logo, quando se fala em escola confessional imediatamente se pensa em escola ligada a uma religião. Considerando que uma escola confessional busca testemunhar e expor, mas não impor sua fé. Ensinar a viver entre as diferenças, acolhendo-as e valorizando-as, é tarefa da escola confessional, sabendo distinguir e conciliar culturas, ciência e fé. Como escola católica entende-se aquela que é dirigida pela autoridade eclesiástica competente ou por pessoa jurídica eclesiástica pública, ou que a autoridade eclesiástica reconhece como tal, mediante documento. A instrução e a educação na Escola Católica fundamentam-se nos principios da doutrina católica; os mestres devem distinguir-se pela retidão de doutrina e probidade de vida (JOÃO PAULO II, 2001, Can. 803 §2). Nenhuma escola pode usar o título de católica sem o consentimento da autoridade eclesiástica competente (LEAL; JUNQUEIRA, 2017, p. 614).

Neste contexto que a pastoral escolar cabe intencionalmente, promover a mediação entre as pessoas e Deus, das pessoas com outras pessoas, e das pessoas consigo mesmas e desta forma, resgatar as esperanças e promover a dignidade do ser humano; por meio de três dimensões: anúncio, serviço e celebração. Este texto visa explicitar a primeira dimensão para o diálogo com as outras duas visando a evangelização no espaço escolar.

\section{0 anúncio e a pastoral no espaço escolar}

O anúncio do Evangelho é missão cristã e compromisso com o mandato do Senhor que concede a todos o direito de conhecer a Boa Nova e usufruir da sua consequência que proporciona a promoção da justiça e a construção de um mundo de paz. Nesta missão se faz necessário manifestar o entusiasmo pela vida de discipulado missionário, que busca realizar o desejo de Jesus: que todos tenham vida e a tenham em abundância! (Jo 10,10). O anúncio, o serviço e a celebração estão presentes em cada etapa da missão do cristão. A pastoral escolar tem a caracteristica de ser o espaço para reflexão, a ação e a missão 
evangelizadora. Nessa missão o evangelizador toma consciência de que o anúncio do Evangelho é um processo complexo, que reúne elementos importantes para sua realização. Esses elementos aparecem na renovação da humanidade, no testemunho e anúncio, no discernimento e por fim nas iniciativas do apostolado.

Neste aspecto é bom ter presente que um dos espaços privilegiados para o anúncio do Evangelho é o espaço escolar, que busca o saber, o conhecer, experimentar e amadurecer para a vida. No espaço escolar, os profissionais da educação, conscientes da sua missão buscam refletir, agir e transformar a atividade educativa em uma forma especial de viver; cresce, em muitos educadores, religiosos e leigos, a consciência de que sua prática educativa precisa ser sempre mais uma presença da Igreja evangelizando o mundo da educação (Conferência Nacional dos Bispos do Brasil, 1987). A grande missão da Igreja é evangelizar e propor a boa notícia do Reino, sob a inspiração do Espírito Santo de Deus e os profissionais das escolas católicas assumem essa responsabilidade diante da missão.

No anúncio do Evangelho, três aspectos importantes fazem a diferença no processo que resulta em beneficio para a sociedade. Começando pela motivação para a mudança interior de cada ser humano, o processo será facilitado e dará abertura aos passos seguintes. Outro ponto importante é a conversão pessoal, sem a qual essa dinâmica não é possivel. E por fim, tão importante quanto os outros passos, está a consciência pessoal e coletiva, motivando a transformação dos critérios e estilos de vida pela força do Evangelho.

Nesse processo é importante buscar o espaço geográfico onde se possa encontrar uma população de grandes dimensões, pois também estes são objetivos da evangelização que procura atingir e modificar os critérios de julgamento e os valores que contrastam com a Palavra de Deus. A pastoral escolar oferece excelentes oportunidades na busca por todos esses objetivos, pois reúne condições essenciais para esta missão. 0 espaço escolar é um ambiente privilegiado para a efetivação da ação evangelizadora. Por fim evangelizar independentemente em relação às culturas, pois quanto mais aberto e acolhedor for o anúncio, maior será a abrangência da evangelização. Porém é necessário ter presente que as técnicas mais avançadas da evangelização, não substituem a ação do Espirito Santo. Mesmo a preparação mais bem elaborada do evangelizador nada consegue fazer, sem a inspiração do Espírito Santo que é o agente principal da evangelização.

Na missão de anunciar o Evangelho está presente a motivação do grande amor de Deus por nós. Aquele amor que foi capaz de dar a própria vida para que pudéssemos ser salvos. O desejo de comunicar a vida, a bondade e os prodígios de Jesus nascem da vontade de retribuir um pouco do que recebemos Dele que é o caminho, a verdade e a vida. O compromisso com o anúncio do Evangelho é a nossa resposta ao pedido de Jesus quando da sua ascensão ao céu.

Naquele tempo, Jesus se manifestou aos onze discipulos e disse-lhes: Ide pelo mundo inteiro e anunciai o Evangelho a toda criatura! Quem crer e for batizado será salvo. Quem não crer será condenado. Os sinais que acompanharão aqueles que creeem serão estes: expulsarão demônios em meu nome, falarão novas linguas; se pegarem em serpentes ou beberem algum veneno mortal não lhes fará mal algum; quando impuserem as mãos sobre os doentes, eles ficarão curados (Mc 16, 15-20). Depois de falar com os discipulos, o Senhor Jesus foi levado ao céu, e sentou-se à direita de Deus. Os discípulos então saíram e pregaram por toda parte. O Senhor os ajudava e confirmava sua palavra por meio dos sinais que a acompanhavam (Mc 16, 15-20).

Assim como os discipulos de Jesus nós também recebemos essa missão e Ele mesmo nos prepara por meio da graça e inspiração do Seu Espirito. O exemplo dos gestos de Jesus, suas atitudes diante dos mais necessitados são inspiração para nossa evangelização. Os Evangelhos trazem um aspecto constante no anúncio de Jesus Cristo. Ele dá ênfase ao fato de que tudo o que pensa, fala ou realiza sempre está em profunda comunhão com o Pai e com o Espírito Santo. Vejamos que Jesus Cristo reúne os após- 
tolos e os envia em nome do Pai e do Filho e do Espírito Santo (Mt 28,19). A iniciativa no anúncio vem de Deus e é Ele que insere o evangelizador nesta iniciativa divina para assim o tornar com Ele anunciador do Evangelho.

Um aspecto importante a ser evidenciado é o de que Jesus, quando envia os apóstolos diz: ide, fazei discipulos meus de todos os povos (Mt 28,19). Jesus não diz fazer discípulos dele todos os povos, mas de todos os povos. Portanto, não há distinção porque, todos são um só em Cristo e isso significa a missão de ir pelo mundo inteiro proclamar, revelar, anunciar, descobrir e plantar as sementes do Evangelho misteriosa e generosamente semeadas pelo Espírito de Jesus no coração de toda a humanidade. O anúncio do Evangelho é um compromisso com o Reino de Deus que é um reino de paz, de amor, de justiça e de fraternidade. Na "Exortação Apostólica Evangelii Nuntiandi", o Papa Paulo VI deixa claro que o anúncio de Jesus, em primeiro lugar foi o anúncio do Reino de Deus. Como evangelizador, Cristo anuncia em primeiro lugar um reino, o reino de Deus, de tal maneira importante que, em comparação com ele, tudo o mais passa a ser o resto, que é dado por acréscimo (EN 16). O anúncio do Evangelho tem a missão de mostrar que é no Evangelho se encontram as respostas para as necessidades da humanidade e em cada ser humano existe o desejo de conhecer as verdades eternas.

O evangelizador é aquele que carrega em si o entusiasmo pelo anúncio do Reino e procura anunciar o evangelho em todos os espaços possiveis, não perdendo nenhuma oportunidade de evangelizar. O Papa Francisco no documento, "A Alegria do Evangelho", sobre o anúncio do Evangelho no mundo atual reforça a importância dos espaços de evangelização destacando que são riquezas inspiradas pelo Espírito Santo, riquezas essas que renovam a Igreja trazendo novo ardor evangelizador. As outras instituições eclesiais, comunidades de base e pequenas comunidades, movimentos e outras formas de associação são uma riqueza da Igreja que o Espírito suscita para evangelizar todos os ambientes e setores. Frequentemente trazem um novo ardor evan- gelizador e uma capacidade de diálogo com o mundo que renovam a Igreja (EG 29).

Os espaços de evangelização merecem atenção especial principalmente porque apresentam novos desafios na realidade atual. Neste aspecto pode-se constatar o desenvolvimento das redes sociais digitais que oportunizam a partilha de ideias, informações, opiniões, novas relações e novas formas de vida fraterna. Esses espaços contribuem com o anúncio do Reino, pois transformam a comunicação em tempo real, favorecendo conexões importantes para a evangelização. Se as redes sociais são chamadas a concretizar este grande potencial, as pessoas que nelas participam devem esforçar-se por serem autênticas, porque nesses espaços não se partilham apenas ideias e informações, mas em última instância a pessoa comunica-se a si mesma (BENTO XVI, 2013). A capacidade de utilizar as linguagens novas do mundo digital se faz necessária porque assim se permitirá o alcance de todos à riqueza infinita do Evangelho.

A Igreja evangeliza quando firmada na potência divina da mensagem que proclama e no testemunho de vida que é o ponto principal no anúncio explícito, feito de uma forma viva e atraente, especialmente para a juventude, que procura o jeito de viver a fé e avalia o anúncio a partir do testemunho dos evangelizadores.

\section{0 anúncio e o serviço pastoral a partir do olhar de Jesus Cristo}

A evangelização começa com o primeiro anúncio, e a pastoral escolar tem a missão de dar continuidade ao anúncio querigmático, pois na nesse espaço é possivel proporcionar a experiência da fé, sedimentar a fé e fortalecer o amor e a adesão ao projeto de Jesus Cristo.

A sociedade pluralista nos apresenta uma grande diversidade de visões da realidade e multiplicidades de concepções de vida. São tantos os desafios encontrados no mundo atual e estes exigem de nós, constantes retomadas de posturas frente aos temas fronteiriços e de eminentes conflitos, que sem sombra de dúvidas, na fraternidade esses temas precisam e 
merecem especial atenção. A realidade atual da comunicação coloca a nossa frente, importantes marcos comportamentais, resultando em grandes desafios para o anúncio do Evangelho, especialmente a partir do olhar de Jesus Cristo.

Percebe-se que hoje há a disponibilidade apenas de fragmentos de linguagens que provocam a reflexão sobre o que e como melhor agir, em determinadas situações para realizar a missão de anunciar o Evangelho. Principalmente entre os mais jovens, parece não haver uma linguagem comum, por meio da qual seja possivel proclamar a missão de Jesus Cristo e atingir seu objetivo. É necessário aprender com a juventude e aproximar-se da melhor forma de conectar-se aos seus anseios para fazer chegar até eles a mensagem do Evangelho.

A grande missão do anúncio é saber perceber o que a sociedade quer dizer e ouvir os seus anseios. Aprender sua linguagem, sentir suas angústias, encontrar soluções e procurar ter atitudes de diálogo onde se compreende e colabora com a evangelização. O ser humano vive em contínua busca da verdade, da paz e da fraternidade e por isso, o diálogo com a sociedade é o fator que dará o significado colaborativo na construção da sua história. Para fazer frente à diversidade e ao pluralismo que caracterizam a realidade atual é necessário oferecer às pessoas uma leitura cristã dos acontecimentos do seu dia a dia.

Outro ponto tão importante quanto esse é saber ler os sinais dos tempos com os critérios evangélicos, para enfrentar os desafios éticos a serviço do bem comum, pois só assim o evangelizador fará chegar Jesus Cristo, com a sua mensagem universal, aos mais diversos segmentos da sociedade.

Os centros universitários também assumem a responsabilidade de evangelizar como forma de educar na fé. Os bispos em Aparecida orientam as universidades católicas quando escrevem: "as atividades fundamentais de uma universidade católica deverão vincular-se e harmonizar-se com a missão evangelizadora da Igreja" (DA 341). Essa é realmente a missão dos anunciadores, que assumindo a mediação da caminhada rumo à edificação do Reino de Deus espalham a esperança e a fé.

No anúncio verdadeiro do Evangelho há a ne- cessidade de inculturar-se, a fim de melhor atingir o objetivo de comunicar a Boa Nova. O próprio Jesus Cristo fez isso e assim Deus vem fazendo ao longo da história. O desafio da evangelização é descobrir e revelar o Evangelho onde ele já pulsa, na cultura e na criação, para novamente ser colocado em cada coração mediante o mistério da encarnação de Jesus. Portanto, não se pode dispor de um único modelo cultural. Permanecer na fidelidade ao anúncio evangélico e assumir o rosto das diversas culturas é o compromisso da evangelização. O Papa Francisco escreve no documento: "A Alegria do Evangelho", sobre o anúncio do Evangelho no mundo atual, o pedido dos bispos da Oceania:

Bispos da Oceania pediram que a Igreja neste continente desenvolva uma compreensão e exposição da verdade de Cristo partindo das tradições e culturas locais e instaram todos os missionários a trabalhar de harmonia com os cristãos indigenas para garantir que a doutrina e a vida da Igreja sejam expressas em formas legítimas e apropriadas a cada cultura. Não podemos pretender que todos os povos dos vários continentes, ao exprimir a fé cristã, imitem as modalidades adotadas pelos povos europeus num determinado momento da história, porque a fé não se pode confinar dentro dos limites de compreensão e expressão duma cultura. É indiscutivel que uma única cultura não esgota o mistério da redenção de Cristo. (EG 118).

Para sermos fiéis ao mandato de Jesus Cristo, precisamos ser capazes de estabelecer conexões com a cultura daquela realidade inserindo nessa missão atitudes dialógicas, a fim de realizar a aproximação dentro da história daquele povo ao qual se deseja conhecer para melhor compreender e atuar de forma adequada. $O$ anúncio precisa carregar em si a capacidade explicita de interagir com a sociedade acolhendo a diversidade cultural na mediação dos sinais do Reino de Deus. Paulo quando fala aos efésios diz: Com toda a humildade e amabilidade, com grandeza de alma, suportando-vos mutuamente com caridade. Sede solícitos em conservar a unidade do Espírito no vínculo da paz. Sede um só corpo e um só espirito (Ef 4, 2-4)

Na evangelização, o valor da diversidade é expressão da inculturação e o exemplo disso está no relato dos Atos dos Apóstolos, quando 
este aponta que cada um dos diferentes grupos étnicos e culturais que se encontravam, na manhã do Pentecostes, reunidos em Jerusalém compreendiam e ouviam a pregação na própria lingua de origem (At 2,6.8.11). Isso comprova o valor da diversidade. O apóstolo Paulo mostra a diversidade de dons e a unidade dinâmica no Espirito: Há diversidade de dons, mas o Espírito é o mesmo. Há diversidade de ministérios, mas o Senhor é o mesmo. Há diferentes atividades, mas é o mesmo Deus que realiza tudo em todos. A cada um é dada a manifestação do Espirito, em vista do bem de todos (1Cor, 4-7).

Um ponto igualmente importante na expressão da presença ativa do Espírito Santo na vida das pessoas é o vínculo de amor, amizade e solidariedade existente em cada comunidade, pois onde o Espírito é acolhido, tudo se transforma em unidade que resulta em efeitos para a coletividade e para as organizações sociais. A afirmação e valorização da diversidade vão ao encontro e também lado a lado com a missão verdadeira do cristão! Deus age em unidade na diversidade e atrai para o Seu serviço, pessoas de todos os ambientes e com inúmeros talentos aproveitando todas as oportunidades para motivar o anúncio do Seu Reino.

Refletindo sobre a importância da aproximação de uma realidade para melhor compreendê-la há a necessidade de um processo cuidadoso, a fim de se atingir o objetivo. Pagola diz para se chegar a uma realidade é necessário fazer um caminho de aproximação em contínuo aperfeiçoamento, assim como no seguimento de Jesus, quando se quer compreender a sua realidade percebe-se que: mediante a investigação histórica não é possivel chegar à realidade total de Jesus; só podemos ir recuperando um retrato incompleto e sempre melhorável de sua atuação (PAGOLA, 2011, p. 14-15).

A realidade cultural no qual Jesus vivia, mesmo sendo somente uma aproximação, ajuda a perceber quais as condições de articulação para o anúncio, que o Mestre precisou ter, a fim de ser mais bem compreendida a sua mensagem. $O$ anúncio do Evangelho a partir do olhar de Jesus cumprirá sua função se houver a aproximação e o aperfeiçoamento na missão onde se possa ir recuperando o retrato mesmo que incompleto da atuação do Mestre e assim, a aproximação dinâmica mostrará que sua vida foi a sua mensagem por excelência e que precisamos ter o olhar de Jesus como Ele olhou do alto da sua cruz. É necessário ler a Escritura e anunciá-la conforme os Seus ensinamentos e o Seu olhar. Anunciar que Jesus veio para todos e que é necessário ter a ousadia de acreditar no Mestre e anunciá-Lo como Caminho, Verdade e Vida.

\section{0 anúncio do Evangelho como forma de educar na fé}

O anúncio do Evangelho é um compromisso muito sério, pois tem como critério a autenticidade de vida que legitimará o discurso por meio do testemunho. A missão de anunciar o Evangelho como forma de educar na fé é realmente uma missão desafiadora e certamente a permanência fiel à proposta do Evangelho exigirá muita convicção, postura coerente, exemplo de vida, testemunho vivo, atenção e comprometimento, possibilitando uma reflexão que supere contradições e propicie espaço para novas propostas nas dimensões transcendentes, sem deixar de vivenciar a realidade.

No espaço escolar, a instituição e seus profissionais se empenham no anúncio do Evangelho, animados pela esperança, mas ao mesmo tempo torturados muitas vezes pelo medo e pela angústia, é sem dúvida alguma um serviço prestado à comunidade dos cristãos, bem como a toda a humanidade (EN 1). Aquele que se propõe a assumir o serviço do Senhor, no anúncio do Evangelho precisa ser fiel e constante nessa tarefa, que também é fruto da convivência fraterna.

Acredita-se que a educação na fé começa no ambiente familiar cristão e se estende em outros espaços do cotidiano, escolas, grupos sociais e profissionais, porém a realidade atual comprova que dificilmente se encontra uma família em condições de propiciar a situação ideal para isso acontecer proporcionando conhecimento e aprofundamento na fé.

A oração, a solidariedade, a fraternidade, a constância e a fidelidade a Palavra de Deus, constituem, 
por assim dizer, a mística que sustenta a vida e a missão daqueles que são anunciadores do Reino.

O Evangelho diz que: "E Jesus crescia em sabedoria, em estatura e em graça, diante de Deus e dos homens" (LC 2, 52). Portanto todas as dimensões do ser humano precisam ser contempladas, desenvolvidas e amadurecidas as áreas do conhecimento, da percepção e da sensibilidade, principalmente nestes tempos em que a sociedade se torna cada vez mais imediatista, com critérios de descartabilidade sofrendo as consequências desse modelo que dilui a autenticidade, a solidez e a verdade, cedendo lugar para a efemeridade e superficialidade da vida, hoje chamada de vida líquida, a sociedade liquida.

Paralelamente, temos ainda a ditadura ou imposição do relativismo, imposição que pode ser feita por meio de armas ou pela mudança de mentalidade, pela cultura. Seria a ideologia do relativismo, o relativismo cultural que provoca mudança de comportamento, de postura e de atitudes. O Papa Bento XVI, no ano de 2005, quando era o Cardeal Joseph Ratzinger, chama a atenção da sociedade para o cuidado com a ditadura do relativismo, que coloca a pessoa como medida de si mesma, não necessitando de Deus o Amor Eterno, o Absoluto que no relativismo não tem vez. O anúncio do Evangelho é a apresentação da pessoa de Jesus Cristo e coloca cada ser humano em um relacionamento de comunhão com Deus e de partilha com os irmãos.

$\mathrm{Na}$ ditadura do relativismo, todos os valores são descartáveis, a crença, a fé, a ética, tudo é descartável, tudo é efêmero e superficial. Lutar contra essa ditadura é o maior desafio na missão evangelizadora. A sociedade está carente de humanização. Os valores estão sendo invertidos devido à falta de referência, referência essa que pode vir de pessoas que se comprometam a educar na fé. Neste sentido se observa o risco do mundo do consumo produzindo tristeza, individualismo, busca desordenada de prazeres superficiais. Falta a verdadeira alegria, de consciência isolada, deixando de haver espaço para os outros. A educação na fé tem o objetivo de promover o encontro pessoal com Jesus e no seu exemplo viver o amor aos irmãos e adquirir a responsabilidade de viver fraternalmente. E o Papa Francisco, traz uma ressignificação do termo ditadura do relativismo, quando em 2013, na audiência com os diplomatas faz menção ao tema:

Como sabeis, há vários motivos que, ao escolher o meu nome, me levaram a pensar em Francisco de Assis. Um dos primeiros é o amor que Francisco tinha pelos pobres. Ainda há tantos pobres no mundo! E tanto sofrimento passam estas pessoas! Mas há ainda outra pobreza: é a pobreza espiritual dos nossos dias, que afeta gravemente também os países considerados mais ricos. É aquilo que o meu Predecessor, o amado e venerado Bento XVI, chama a 'ditadura do relativismo', que deixa cada um como medida de si mesmo, colocando em perigo a convivência entre os homens. E assim chego à segunda razão do meu nome. Francisco de Assis diz-nos: trabalhai por edificar a paz. Mas, sem a verdade, não há verdadeira paz. Não pode haver verdadeira paz. se cada um é a medida de si mesmo, se cada um pode reivindicar sempre e só os direitos próprios, sem se importar ao mesmo tempo do bem dos outros, do bem de todos, a começar da natureza comum a todos os seres humanos nesta terra (FRANCISCO, 2013).

O Papa Francisco fala da verdade, da busca pelo bem comum, na vivência da solidariedade, da fraternidade, na busca da dignidade humana e da verdade pela prática da justiça e da paz. É preciso continuar a ousadia de crer em Jesus e anunciá-Lo como o Caminho, a Verdade e a Vida. Anunciar a Palavra é sinal de que nela se acredita e se vive na certeza da edificação do Reino de Deus.

\section{Anunciar e celebrara a Boa Nova com o olhar de Jesus}

Anunciar a Boa Nova é o mandato do Senhor: Como poderiam crer se não ouviram? E como poderiam ouvir sem pregador? E como podem pregar se não foram enviados? Como está escrito: Quão maravilhosos os pés dos que anunciam boas notícias (Rm 10,14-15). Essa foi indiscutivelmente a principal atividade dos apóstolos, que foi seguida pelos cristãos. Anunciar Jesus é trazer esperança, alegria e ver longe, saber olhar além e também olhar de perto para ver as necessidades permanecendo atentos aos desafios enfrentados pelos irmãos, a fim de viver e anunciar o mandamento do amor. 
A escola católica é um espaço privilegiado para o anúncio do Evangelho, pois nela se encontra um importante instrumento de evangelização e a pastoral escolar tem um papel fundamental nessa missão. Na sua ação deve estar presente a marca cristã e em sua visão de mundo precisa estar contemplada a proposta do Evangelho. A evangelização na escola católica objetiva estabelecer meios para que se redescubra o lugar do sagrado na vida das novas gerações, despertando respeito e desenvolvendo o senso crítico, a partir das verdades da fé encontradas na mensagem do Evangelho e na pessoa de Jesus Cristo, para assim ser sinal visível do Reino de Deus.

Ai de mim se não evangelizar (1Cor 9, 16). Esse foi o desabafo de Paulo na "Carta aos Coríntios" e na "Carta aos Romanos", Paulo afirma que a fé vem da pregação e ainda reforça que a pregação é feita pela palavra de Cristo; pela terra inteira correu sua voz; até os confins do mundo as suas palavras (Rm 10.17-18). A experiência do amor de Deus gera em nós um movimento que nos impele a partilhar as maravilhas do amor de Deus. Disse o Papa Francisco durante o Ano da Misericórdia, que devemos vencer a cegueira da aparência e vencer as tristezas, tornando-nos: sensiveis aos pobres, que não são um apêndice do Evangelho, mas página central, sempre aberta diante de nós (FRANCISCO, 2016). Francisco, em sua "Exortação Apostólica Evangelii Gaudium" ressalta o compromisso cristão da alegria no anúncio que traz vida em plenitude.

A Alegria do Evangelho enche o coração e a vida inteira daqueles que se encontram com Jesus. Quantos se deixam salvar por Ele são libertados do pecado, da tristeza, do vazio interior, do isolamento. Com Jesus Cristo, renasce sem cessar a alegria. Quero, com esta Exortação, dirigir-me aos fiéis cristãos a fim de os convidar para uma nova etapa evangelizadora marcada por esta alegria e indicar caminhos para o percurso da Igreja nos próximos anos (FRANCISCO, 2013).

A missão do cristão é anunciar a todos, o amor e a ternura de Jesus no apostolado da alegria do Evangelho, que é contagiante. Francisco ressalta que o desígnio de Deus nos atrai para a alegria do encontro com Ele, mesmo na fragilidade humana: Deus nunca se cansa de perdoar, somos nós que nos cansamos de pedir a sua misericórdia. Ele permite-nos levantar a cabeça e recomeçar, com uma ternura que nunca nos engana e sempre nos pode restituir a alegria (EG 3). Os discipulos missionários, anunciadores da Boa Nova, promovem alegria partilhando a experiência da gratuidade de Deus e sentindo reacender-se sempre de novo, a vontade de transmiti-la aos outros porque sabem que este é o Caminho, a Verdade e a Vida.

Dentre os desafios e perspectivas do anúncio podemos ressaltar a evangelização com o cultivo da espiritualidade e o desenvolvimento de ações missionárias envolvendo projetos concretos, para a valorização das diversas culturas na transmissão da fé cristã. Realmente são muitos os desafios e o evangelizador tem a missão de discernir, sob a ação do Espírito Santo, os passos a serem dados em favor da paz e do bem, para a humanidade tendo como horizonte o olhar de Jesus.

Um aspecto importante no anúncio do Evangelho é a necessidade de atenção ao fenômeno da realidade atual na população mais jovem, que direciona a forma cultural e influencia no modo de entender, ler, interpretar e viver a fé cristã dentro desta realidade. Esse processo está em andamento e influencia diretamente as novas gerações, com as características específicas de proximidade com a diversidade, de todas as formas, às vezes até de forma conflitiva, mas é legítima e oferece possibilidades de escolhas diversas, sempre de acordo com os valores que o jovem acredita.

As parábolas de Jesus dependem muitas vezes do envolvimento de alguns de nossos sentidos, principalmente o da imaginação e da sensibilidade afetiva, a fim de se conseguir uma comunicação eficaz no ministério de anunciar o mistério do amor de Deus. A tradição cristã é rica em sinais e símbolos que procuram exprimir as verdades da fé e, portanto, a moderna linguagem digital proporciona um leque de recursos que sendo bem utilizados irão favorecer o anúncio do Evangelho para o desenvolvimento da missão evangelizadora.

Esse é o verdadeiro sentido do anúncio: aquele que, para além das diferenças, é capaz de ver e capaz de acolher com alegria e júbilo a presença, o amor e o espírito que é Deus, que é Pai, em 
cada povo, realidade, cultura ou pessoa, mesmo naqueles que não $\mathrm{O}$ aceitam e até o rejeitam, talvez porque o queiram agredir, maltratar e condenar. Essa evangelização que respeita as diferenças, que enxerga além do aparente, esta realmente foi a evangelização que revolucionou a humanidade, pelo seu diferencial.

Na evangelização, a inculturação vai expressar o valor da diversidade, que na influência reciproca entre as culturas garante a prática da fé cristã em toda a sua riqueza, na unidade da diversidade. Nunca se pode esquecer que entre a tolerância e a intolerância está a dignidade da pessoa humana. O Evangelho é compreensivel para todas as pessoas porque Jesus veio para todos e os anunciadores aprenderão muito de todas as civilizações. A alegria do Evangelho contém sempre a dinâmica do êxodo e do dom, de sair de si mesmo, de caminhar e de semear sempre de novo, semear sempre mais além (EG 21). Esse movimento de ir além, de sair de si, de sair do seu mundo, da sua zona de conforto é o movimento de articulação, de conexão com a sociedade em atitude dialogal, a fim de interagir e mediar a edificação do Reino de Deus.

O anúncio do Evangelho requer o espaço onde se possa falar da convicção e da fé cristã. Espaço este que precisa reunir condições de vida e de verdade na fé. A Escola Católica é um desses espaços privilegiados, pois nesse espaço se encontram aqueles que buscam os conhecimentos das ciências e da fé, abrindo caminhos para a evangelização.

\section{Considerações finais}

Ao final desta reflexão fica evidente a característica do anúncio a partir do olhar de Jesus. Ele que não fez distinção de ninguém, pois todos somos irmãos, portanto, procurando agir como Jesus, o objetivo da evangelização será alcançado. O anúncio do Evangelho comporta a capacidade de interagir com a sociedade e acolhe a diversidade cultural assumindo a mediação da caminhada rumo à edificação do Reino de Deus. $O$ anúncio do Evangelho exige o encarnar-se na cultura própria de cada espaço onde se quer evangelizar.
Anunciar a proposta de Jesus Cristo que veio para que todos tenham vida em plenitude é a missão do cristão. O anúncio do Evangelho como forma de educar na fé é compromisso com o testemunho de vida. Evangelizar é divulgar e propor a boa notícia do Reino de Deus sob a inspiração do Espírito Santo.

No processo do anúncio, os aspectos de mudança interior, conversão, consciência pessoal e coletiva, são importantes porque proporcionarão efeitos que beneficiarão a sociedade. O espaço evangelizador da Escola Católica pode e precisa ser motivador, a fim de ser exemplo de seguimento, presença atuante e testemunho de vida e de serviço.

Os desafios encontrados na atualidade exigem de nós, constantes retomadas de posturas frente aos temas fronteiriços e de eminentes conflitos, que na fraternidade precisam de especial atenção. A realidade atual coloca a nossa frente, importantes transformações comportamentais para evangelizar a partir do olhar de Jesus Cristo.

A experiência de quem anuncia o Evangelho é sempre de compromisso e de partilha com os irmãos. Na dimensão transcendente os anunciadores da Boa Nova partilham a experiência de Deus e sentem vontade de transmiti-la, por terem a certeza de que este é o Caminho, a Verdade e a Vida. Quão maravilhosos os pés dos que anunciam boas notícias (Rm 10,14-15).

Acolher as diferenças, promover a unidade e comunhão entre os irmãos, conjugar os valores da liberdade, da fraternidade, da justiça, da solidariedade, da igualdade, da pluralidade, da coexistência, da paz, da tolerância, da verdade, são os grandes desafios e o evangelizador tem a missão de discernir, sob a ação do Espírito Santo, os passos a serem dados em favor da humanidade tendo como horizonte o olhar de Jesus. Aqui também há que se ressaltar que a Pastoral Escolar contribui para o desenvolvimento de atitudes que potencializam tanto os educandos e suas famílias, quanto os docentes e colaboradores no que se refere aos valores e sentidos humanitários.

O anúncio do Evangelho exige o encarnar-se na cultura própria de cada espaço, a fim de fazer 
acontecer a verdadeira evangelização. A inculturação, expressão do valor da diversidade, irá permitir que a dignidade humana seja preservada em todos os ambientes e situações que a vida apresentar. Ai de mim se não evangelizar (1Cor 9 , 16). Para continuar a missão de Cristo, é necessária a semelhança com Ele e somente o Espírito Santo pode transformar o evangelizador tornando-o semelhante a Cristo. Ele nos leva a atingir o estado de homem perfeito, a estatura e maturidade de Cristo (Ef 4,1). Continuar a missão de Cristo é compromisso sério e desafiador, mas o Espírito de Deus tornará possível a realização da missão.

\section{Referências}

BENTO XVI, Papa. Mensagem de sua Santidade para o $47^{\circ}$ Dia Mundial das Comunicações Sociais. Vaticano, maio 2013.

BIBBLIA SAGRADA. Edição Pastoral. Tradução de Storniolo, Ivo. Blancin, Euclides Martins. São Paulo: Paulinas, 1986.

BRASIL. [Constituição (1988)]. Constituição da República Federativa do Brasil. Brasilia, DF: Senado Federal, 1988.

BRASIL. Lei n. ${ }^{\circ}$ 9394, de 20 de dezembro de 1996. Estabelece as diretrizes e bases da educação nacional (Lei de Diretrizes e Bases da Educação Nacional). Brasília, DF: Presidência da República, 1996.

CELAM. Documento de Aparecida, n. 341. V Conferência Geral do Episcopado Latino-Americano e do Caribe, Aparecida, 2007.

CNBB. Educação, Igreja e sociedade, Coleção estudos da CNBB; n. 49. O ensino religioso nas constituições do Brasil nas legislações de ensino e nas orientações da Igreja. São Paulo: Paulinas, 1987.

FRANCISCO, Papa. Exortação Apostólica, Evangelii Gaudium. Roma, 2013.

FRANCISCO. O domingo, 25 de setembro, foi um dos dias mais aguardados, quando todos se dirigiram à Praça São Pedro para participar da missa presidida pelo Papa Francisco. 2016.

JOÃO PAULO II. Código de Direito Canônico. São Paulo: Loyola, 2001

LEAL, Valéria; JUNQUEIRA, Sérgio. A Escola Confessional Católica Romana. Revista Pistis \& Praxis, Curitiba, v. 9. n. 3, p. 611-628, set./dez. 2017.

PAGOLA, José Antônio. Jesus: aproximação histórica. Petrópolis: Vozes, 2011

PAULO VI. Exortação Apostólica sobre a Evangelização no mundo contemporâneo Evangelii Nuntiandi. São Paulo: Paulinas, 1975

RATZINGER, Joseph. Mensagem ao presidir a Missa na Basílica de São Pedro. Vaticano, abr. 2005.

\section{Sérgio Rogério Azevedo Junqueira}

Doutor em Ciências da Educação pela Università Pontificia Salesiana (UPS), em Roma, Itália. Livre docente e pós-doutor em Ciência da Religião na Pontifícia Universidade Católica de São Paulo (PUCSP), em São Paulo, SP, Brasil. Pós-Doutor em Geografia Cultural pela Universidade Federal do Paraná (UFPR), em Curitiba, PR, Brasil. Diretor do Instituto de Pesquisa e Formação Educação e Religião (IPFER), em Curitiba, PR, Brasil.

\section{Terezinha Sueli de Jesus Rocha}

Mestre em Teologia pela Pontifícia Universidade Católica do Paraná (PUCPR), em Curitiba, PR; Brasil. Pesquisadora no Instituto de Pesquisa e Formação Educação e Religião (IPFER), em Curitiba, PR, Brasil.

\section{Endereço para correspondência}

Sérgio Rogério Azevedo Junqueira/

Terezinha Sueli de Jesus Rocha

GPER - Serviços Educacionais

Rua das Tropas, 141

Guabirotuba, 81520370

Curitiba, PR, Brasil

Os textos deste artigo foram submetidos para validação dos autores antes da publicação. 